\title{
Cellulose Based Cation-Exchange Fiber as Filtration Material for the Rapid Removal of Methylene Blue from Wastewater
}

\section{Xinyi Shao}

Shaanxi University of Science and Technology Xi\'an Campus: Shaanxi University of Science and Technology

Jian Wang ( $\square$ zzwangjian@sust.edu.cn )

Shaanxi University of Science and Technology https://orcid.org/0000-0003-1827-0239

Zetan Liu

Shaanxi University of Science and Technology Xi\'an Campus: Shaanxi University of Science and Technology

$\mathrm{Na} \mathrm{Hu}$

Shaanxi University of Science and Technology Xi\'an Campus: Shaanxi University of Science and Technology

Min Liu

Shaanxi University of Science and Technology Xi\'an Campus: Shaanxi University of Science and Technology

Chao Duan

Shaanxi University of Science and Technology Xi\'an Campus: Shaanxi University of Science and Technology

\section{Ruimin Zhang}

Shaanxi University of Science and Technology Xil'an Campus: Shaanxi University of Science and Technology

\section{Cailin Quan}

Shaanxi University of Science and Technology Xi\'an Campus: Shaanxi University of Science and Technology

\section{Original Research}

Keywords: cellulose, fibrous adsorbent, solid/liquid separation, bio-adsorbent, dye-containing wastewater

Posted Date: February 3rd, 2021

DOl: https://doi.org/10.21203/rs.3.rs-190532/v1 
License: (c) (i) This work is licensed under a Creative Commons Attribution 4.0 International License. Read Full License

Version of Record: A version of this preprint was published at Cellulose on August 5th, 2021. See the published version at https://doi.org/10.1007/s10570-021-04103-2. 


\section{Cellulose Based Cation-Exchange Fiber as Filtration Material for the} Rapid Removal of Methylene Blue from Wastewater

b: National Demonstration Center for Experimental Light Chemistry Engineering Education, Shaanxi University of

Science \& Technology, Xi'an 710021, China

*Corresponding author: Tel: +86-18229003848

E-mail: zzwangjian@sust.edu.cn

\section{Abstract}

The development of eco-friendly adsorbent with perfect solid/liquid separation performance is of great practical importance for the efficient purification of dye-containing wastewater. Herein, cellulose based cation-exchange fibrous bio-adsorbent (CEF) was successfully obtained via an industrialized cellulose etherification process. The fiber morphology can be maintained with the average degree substitution (DS) of CEF as about 0.19. The CEF showed high efficiency adsorption for methylene blue (MB): achieving $82 \%$ of equilibrium uptake (447.69 $\left.\mathrm{mg} \cdot \mathrm{g}^{-1}\right)$ within $5 \mathrm{~min}$. Especially, the non-woven porous filter material, formed by CEFs and glass fibers, showed the praisable solid/liquid separation characteristics, fast water filtration rate $\left(\approx 6.3 \mathrm{~m}^{3} \cdot \mathrm{m}^{-2} \cdot \mathrm{h}^{-1}\right)$ and high removal rate $(\approx 99.2 \%)$ when it was used to adsorb MB (150 ppm) from wastewater. In addition, CEFs filter material can be regenerated via a simple method. This study demonstrates that green natural fiber materials are promising for the economical and efficient purification of dye-containing wastewater. 


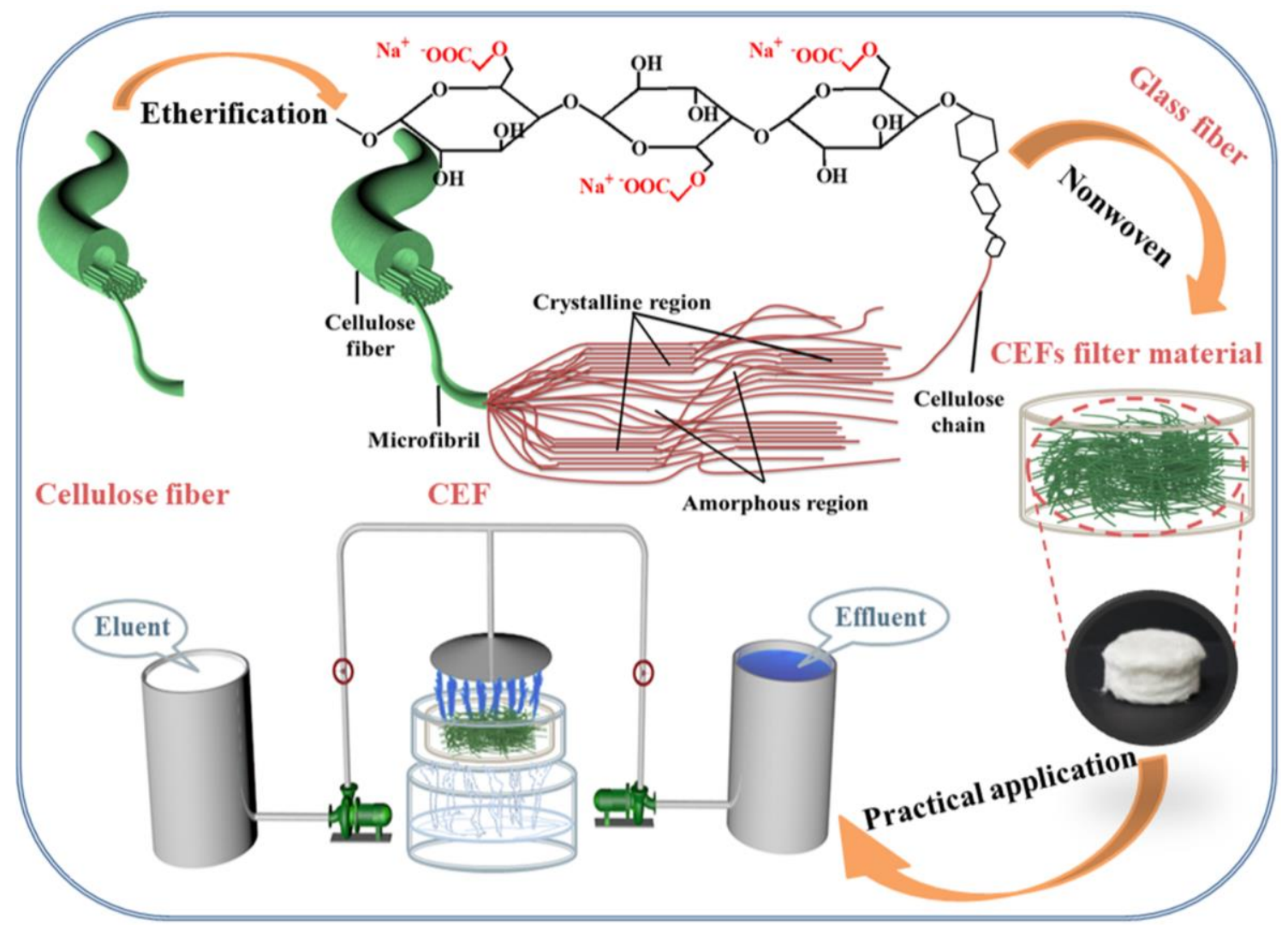

Key words: cellulose, fibrous adsorbent, solid/liquid separation, bio-adsorbent, dye-containing

wastewater

\section{Introduction}

Water is the source of life, but unfortunately, water sources are threatened from contaminants and pollutants that are discharged into rivers due to industrialization (Jovan et al. 2019; Qi et al. 2019).

Synthetic dyes, which are widely used in the textile, printing and plastic industries, are regarded as one of the most notorious pollutants on account of their high toxicity, high chroma and non-degradability (Huang et al. 2019). Thus, how to resolve dye pollution in wastewater has become an urgent issue. Various techniques have been applied for the wastewater treatment, including biologic treatment (Abiri et al., 2016; 
2015), membrane separation (Neethu et al., 2018) and adsorption (Jia et al., 2020). Among these, adsorption has been regarded as one of the most effective and competitive method due to its low cost, easy separation and high efficiency. At present, many adsorbent materials have been investigated, including conventional materials such as activated carbons (Peláez-Cid et al. 2016) and clay minerals (Li et al. 2018), advanced materials such as metal-organic frameworks (MOFs) (Oveisi et al. 2017), reduced graphene oxide/titanium dioxide nanotubes (rGO/TNT) (Nguyen and Juang, 2019) and low-spin-state hematite(Shen et al. 2020). Nevertheless, there is still need for further exploration on the adsorbents with sustainability, economy, nontoxicity and renewability.

Biomass raw materials are the most promising adsorbents to meet above requirements. Bio-adsorbents have been investigated to treat dye-containing wastewater, including forest and agricultural residues (Haque et al. 2020), hemicellulose (Sun et al. 2015), protein (Liu et al. 2016a), lignin (Tang et al. 2014), chitosan (Leon et al. 2018; Chen et al. 2020), cellulose (Li et al. 2018) etc. Cellulose, the most abundant biomass in nature, has received much attention in the development of these green bio-adsorbents (Chen et al. 2016).

To this end, abundant specific functional groups in these structures are critical. For example, the cellulose modified with glycidyl methacrylate and sulfosalicylic acid leads to bio-adsorbent, with adsorption equilibrium for crystal violet of about $135 \mathrm{mg} \cdot \mathrm{g}^{-1}$ that is reached in $150 \mathrm{~min}$ (Zhou et al. 2014). Amino-modified nanocellulose microgel achieved adsorption equilibrium of $200 \mathrm{mg} \cdot \mathrm{g}^{-1}$ for Congo red within $1 \mathrm{~h}$ (Xu et al. 2015). Phosphate-modified cellulose powder reached the adsorption equilibrium of $46.95 \mathrm{mg} \cdot \mathrm{g}^{-1}$ for rhodamine $\mathrm{B}(\mathrm{RhB})$ in $65 \mathrm{~min}$ (Silva et al. 2020). Carboxymethyl cellulose-graphene oxide (CMC-rGA) aerogel showed a high absorption activity for $\mathrm{RhB}$ with $186.33 \mathrm{mg} \cdot \mathrm{g}^{-1}$ (Xiang et al. 

$\mathrm{mg} \cdot \mathrm{g}^{-1}$ for MB with the contact time of $10 \mathrm{~h}$ (Sabarish et al. 2018).

However, most of cellulose based bio-adsorbents studied so far are in the form of aerogel, hydrogel, wastewater needs to penetrate through multiple pore walls. The water filtration rate of membrane is fast, but its adsorption capacity is insufficient due to its small thickness. For particle, in order to have more adsorption sites, it is necessary to reduce the volume to increase the specific surface area, resulting in the difficulty of solid/liquid separation. The existing forms of cellulose based bio-adsorbents limit their practical application. Compared with them, fibrous bio-adsorbents have shown irreplaceable advantage owing to their perfect solid/liquid separation property, fast water filtration rate and superior wastewater treatment performance in terms of adsorption capacity and removal rate.

In this work, the cation-exchange fiber (CEF) based on cellulose were prepared via an industrialized cellulose etherification process using chloroacetic acid as the etherifying agent. The model cationic dye (MB) was employed to investigate the adsorption properties of CEF. Furthermore, a filter material expected to have perfect solid/liquid separation performance was formed by CEFs and glass fibers via non-woven way. The aim of this work is to provide a new strategy for using green and biodegradable natural fiber materials as promising bio-adsorbents for cost-effective and rapid purification of dye-containing wastewater.

\section{Experimental}

\section{Materials}


China. Reagent grade sodium chloroacetate (MCA) (AR, $\geq 98 \%$ ), sodium hydroxide (AR, $\geq 96 \%$ ), hydrochloric acid (AR, $\geq 36.0 \%$ ), Methylene blue (Ind) and ethanol were received from Aladdin Reagent

81 Co., Ltd (Shanghai, China). Glass fibers (length: $5 \mathrm{~mm}$, width: $26 \mu \mathrm{m}$ ) were obtained from Hengguang Co., Ltd (Shi Jia Zhuang, China). Deionized water was used throughout this work.

\section{Synthesis of cellulose based cation-exchange fiber (CEF)}

$10 \mathrm{~g}$ softwood kraft pulp fibers, $15 \mathrm{~g}$ MCA and deionized water $(20 \mathrm{~mL})$ were added into beaker.

The reaction was carried out at $60^{\circ} \mathrm{C}$ water bath for $2 \mathrm{~h}$. Then the sample was immersed in the mixture solution $(\mathrm{NaOH}: 12.5 \mathrm{~g}$, deionized water: $20 \mathrm{~mL})$. The reaction was performed at $80^{\circ} \mathrm{C}$ for $8 \mathrm{~h}$. The production was wished with ethanol to neutral, and finally air-dried.

\section{Preparation of CEFs filter material}

A porous filter material was formed by CEFs and glass fibers (weight ratio $=2: 1$ ) via non-woven

way. The specific operation was that CEFs and glass fibers were fully dispersed in water, then filtered to remove excess water and dried in the oven at $60^{\circ} \mathrm{C}$.

\section{Characterization} was carried out to analyze the functional group, the spectrum ranges from 500 to $4000 \mathrm{~cm}^{-1}$. The surface morphology of materials was observed by optical microscope (DMB5, Motic Co. Ltd., Xiamen, China). The energy dispersive spectrometer (EDS, VEGA $3 \mathrm{SBH}$ ) was used to analyze the elementary composition. The morphological properties of fibers were determined by the Fiber \& Shive Analyzer 
measured by UV-vis spectrophotometer (UV-5000, Agilent, USA). The surface charges of fibers were measured by using a particle charge detector (PCD-03, Mütek, Germany). Zeta potential was determined by using a Zeta Nanosizer (SZTP06, Germany). The crystal structure of materials was analyzed by X-ray diffraction (XRD, D8 Advance, Bruker, Germany) at a scan rate of $0.02^{\circ} \cdot \mathrm{min}^{-1}$. The crystallinity index (CrI) of the sample was calculated using the following equation (Liu et al. 2016b):

$\operatorname{CrI}=\left(I_{002}-I_{a m}\right) / I_{002} \times 020$

Here $\mathrm{I}_{002}$ is the maximum diffraction intensity of crystalline from plane (002) at $2 \theta=22.7^{\circ}$ for cellulose $\mathrm{I}$, and $2 \theta=21.7^{\circ}$ for cellulose II, while $\mathrm{I}_{\mathrm{am}}$ is the intensity of amorphous cellulose at $2 \theta=18^{\circ}$ for cellulose $\mathrm{I}$, and $2 \theta=16^{\circ}$ for cellulose II (Segal et al. 1959).

\section{Carboxyl group content}

The content of carboxyl group was determined by using standard method TAPPI T 237 with some appropriate modifications to suit the high carboxyl group content of CEF. Specifically, the amount of content of the fiber was calculated according to the following modified equation:

114 Carboxyl content $\left(\mathrm{mmol} \cdot 100 \mathrm{~g}^{-1}\right)=\left[B-\left(A+A \times \frac{c}{100}\right)\right] \times N \times \frac{400}{W}$

115 where $A(\mathrm{~mL})$ is the volume of $0.010 \mathrm{~N} \mathrm{HCl}$ consumed in titration of the pulp filtrate $(25 \mathrm{~mL}) ; B(\mathrm{~mL})$ is

116 the volume of $0.010 \mathrm{~N} \mathrm{HCl}$ consumed in titration of the sodium bicarbonate-sodium chloride solution (25

$117 \mathrm{~mL}) ; C(\mathrm{~g})$ is the weight of water in pulp pad; $\mathrm{N}$ is the normality of $\mathrm{HCl}$ used in titration; $W(\mathrm{~g})$ is the weight of oven-dried test specimen; $100(\mathrm{~mL})$ is the amount of sodium bicarbonate-sodium chloride 119 solution; 400 is derived as $4 \times 100$, where 4 is a factor to account for $25 \mathrm{~mL}$ aliquot taken for titration, and 100 is to express the result on $100 \mathrm{~g}$ of pulp. 


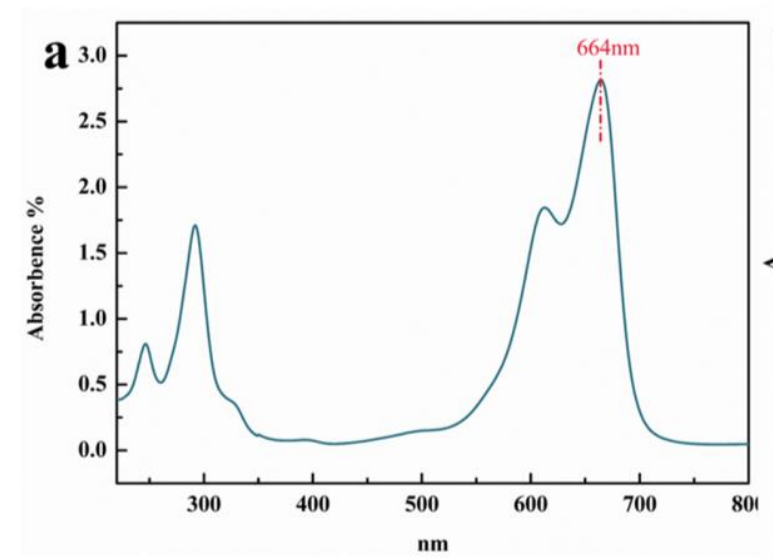

\section{Adsorption experiments}

$q=\frac{\left(C_{0}-C_{t}\right) \times V}{m}$

To study the adsorption capacity of CEF, a typical cationic dye MB was used. The maximum adsorption wavelength of MB was measured by UV-vis spectroscope. Subsequently, the absorbance-concentration (A-C) curve for MB was determined on the basis of the maximum absorption wavelengths of $664 \mathrm{~nm}$, which was showed in Fig. 1. First of all, $20 \mathrm{mg}$ CEF was added in $50 \mathrm{~mL} \mathrm{MB}$ solution (initial concentration: $200 \mathrm{ppm}$ ) and stirred $30 \mathrm{~min}$ at room temperature. The $\mathrm{pH}$ value of MB was adjusted by $0.1 \mathrm{~N} \mathrm{HCl}$ and $\mathrm{NaOH}$. The residual concentration of the dye was detected using UV-vis spectrophotometer at $664 \mathrm{~nm}$. The adsorption capacity of MB was calculated by

Where $q$ is the adsorption capacity of $\mathrm{MB}\left(\mathrm{mg} \cdot \mathrm{g}^{-1}\right) ; V$ is the solution volume $(\mathrm{L}) ; C_{0}$ is the MB initial concentration $\left(\mathrm{mg} \cdot \mathrm{L}^{-1}\right) ; C_{t}$ is the $\mathrm{MB}$ concentration at time $\mathrm{t}\left(\mathrm{mg} \cdot \mathrm{L}^{-1}\right) ; m$ is the weight of adsorbent $(\mathrm{g})$.

Fig. 1. (a) UV-Vis spectra of MB; (b) A-C curves of MB. models (Eq. (5)), shown as follows: 
$136 \quad \frac{t}{q_{t}}=\frac{1}{K_{2} q_{e}^{2}}+\frac{1}{q_{e}} t$

137 Where $q_{e}$ and $q_{t}$ are the amounts of dye adsorbed on the CEF at equilibrium and at time t, respectively; $K_{l}$

138 and $K_{2}$ are the rate constant of the pseudo-first-order and pseudo-second-order $\left(\mathrm{g} \cdot \mathrm{mg}^{-1} \cdot \mathrm{min}^{-1}\right)$,

139 respectively.

140 Adsorption isotherms

141 The adsorption isotherm was detected by Langmuir (Eq. (6)) and Freundlich (Eq. (7)) models,

142 respectively, the linear equations are presented below:

$143 \quad \frac{C_{e}}{q_{e}}=\frac{C_{e}}{q_{m}}+\frac{1}{q_{m} K_{L}}$

$144 \quad \ln q_{e}=\frac{1}{n} \ln C_{e}+\ln K_{F}$

145 Where $q_{e}$ and $q_{m}$ are the amounts of dye adsorbed on the CEF at equilibrium and the maximum saturated

146 monolayer sorption capacity of adsorbent, respectively; $K_{L}$ and $K_{F}$ are the rate constant of the

147 pseudo-first-order and pseudo-second-order, respectively.

Adsorption thermodynamics

150 values of $\Delta \mathrm{H}^{0}$ and $\Delta \mathrm{S}^{0}$ could be derived from the formula:

$151 \Delta G^{0}=-R T \ln K^{0}$

$152 \quad \ln K^{0}=\frac{\Delta S^{0}}{R}-\frac{\Delta H^{0}}{R T}$

153 Where $R$ is ideal gas constant $\left(8.314 \mathrm{~J} \cdot \mathrm{mol}^{-1} \cdot \mathrm{K}^{-1}\right) ; T$ is the Kelvin temperature $(\mathrm{K}), \Delta G^{0}\left(\mathrm{KJ} \cdot \mathrm{mol}^{-1}\right)$ is the standard Gibbs free energy change; $K^{0}$ was the thermodynamic equilibrium constant; $\Delta S^{0}\left(\mathrm{KJ}^{\prime} \mathrm{mol}^{-1}\right)$ was the standard entropy change; $\Delta H^{0}\left(\mathrm{~J} \cdot \mathrm{mol}^{-1} \cdot \mathrm{K}^{-1}\right)$ is the standard enthalpy change. 


\begin{tabular}{ccc}
\hline Samples & Length $/ \mathrm{mm}$ & Width $/ \mu \mathrm{m}$ \\
\hline Cellulose fiber & $1.814 \pm 0.034$ & $29.8 \pm 0.4$ \\
CEF & $1.683 \pm 0.052$ & $38.2 \pm 0.9$ \\
\hline
\end{tabular}

temperature to desorb the MB. Then it was washed with deionized water for several times until the $\mathrm{pH}$ was closed to natural, and dried for next test. This process was recycled four times. The regeneration efficiency (\%RE) of adsorbent was calculated as follows:

$R E \%=\frac{q_{r}}{q_{0}} \times 100 \%$

Where $q_{0}$ and $q_{r}\left(\mathrm{mg} \cdot \mathrm{g}^{-1}\right)$ are the adsorption capacities of the original adsorbent and regenerated adsorbent, respectively.

\section{Results and discussion}

\section{The morphological properties of fibers}

As shown in Fig. 2a and b, CEF has the similar fibrous morphology as original cellulose fiber. Compared with cellulose fiber (Table 1), the average length of CEF was slightly decreased, which was due to the uneven reaction of fibers during etherification and the parts with violent reaction might be broken. In addition, the increasing of carboxyl content improves the hydrophilicity and water-swollen ability of the fiber, leading to a significant increase in the fiber width during the detection using water as medium. The cross-sectional morphology of CEF was observed by laser scanning confocal microscope (LSM). Fig. 2c clearly shows that CEF has a complete cell cavity, further confirming that the fibrous structure is still maintained after etherification.

Table 1 Basic morphological characteristics of fibers before and after etherification. 

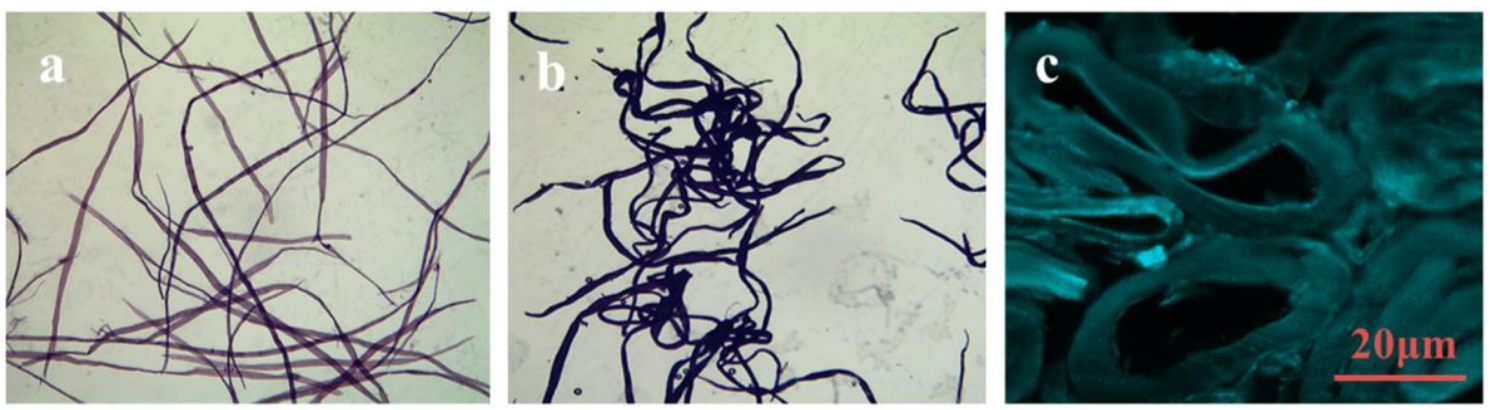

Fig. 2. The optical micrographs of (a) cellulose fibers $(\times 40)$ and (b) CEFs $(\times 40)$. (c) The cross-sectional of CEFs

(with fluorescent active labelling).

The carboxyl group content and zeta potential of fibers

It is well known that two phases coexist within the aggregation structure of cellulose is the reason why cellulosic biomass is insoluble in water. Table 2 showed that the total charges of fibers increased from $4.96 \mathrm{mmol} / 100 \mathrm{~g}$ sample to $107.64 \mathrm{mmol} /{ }_{100 \mathrm{~g} \text { sample }}$ after carboxymethylation. According to Eq. (S1), the average degree of substitution (DS) of CEF is about 0.19 , indicating that a small part of the hydroxyl groups on the cellulose molecular chains are substituted. It is speculated that CEF is still an aggregation structure with coexistence of two phases, which is the reason why CEF can maintain fibrous structure. The low DS makes the functionalized cellulose fiber still retains a large number of crystalline regions of original cellulose.

The introduction of carboxyl groups makes CEFs are strongly negatively charged on their surfaces, and the zeta potential is $-38.3 \mathrm{mV}$, which is compared to $-17.8 \mathrm{mV}$ for the original cellulose fibers. The increased negative charges on CEFs surfaces lead to stronger electrostatic interactions with cationic substance. 
Table 2 The carboxyl group content and zeta potential value of fiber before and after etherification.

Samples

Carboxyl group content (the total charges)/ mmol / $100 \mathrm{~g}$ sample

$\mathrm{CEF}$

\section{XRD analysis}

The destruction of Cellulose I was confirmed from X-ray diffraction (XRD) patterns (Fig. 3). The peaks at $2 \theta=15^{\circ}$ and $22.5^{\circ}$ correspond to the crystal planes of (101) and (002) respectively, which are the characteristic peaks of Cellulose I. After etherification, the presence of a new diffraction peak at $2 \theta=20^{\circ}$, crystallinity is reduced to about $56.64 \%$. This result is in consistent with the above speculation, which is that CEF still has a two-phase coexisting aggregation structure in the case of considerable carboxyl group groups in the cell wall, facilitating the effective adsorption.

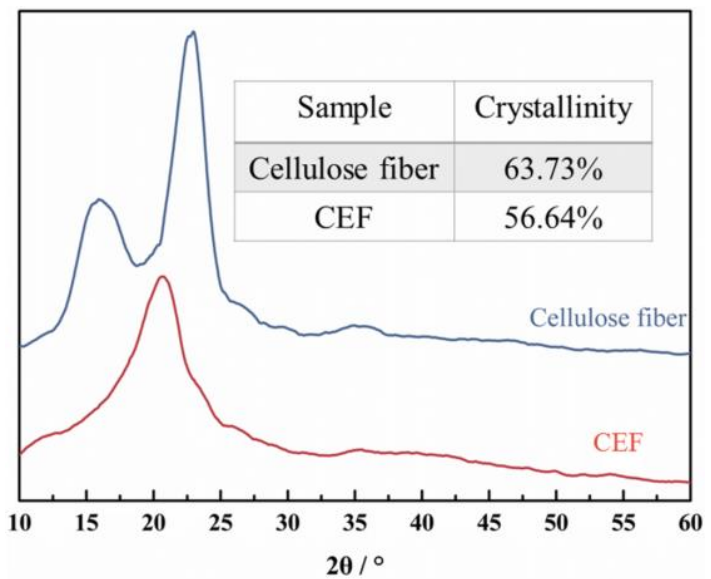

Fig. 3. XRD spectra of cellulose fiber and CEF. 


\section{FTIR analysis and EDS analysis}

The successful load of MB on CEF is confirmed by FTIR and EDS results. FTIR experimental

results show that no covalent bonds are formed between $\mathrm{CEF}$ and $\mathrm{MB}$, indicating that electrostatic interactions might be the main force. As shown in Fig. 4id, the characteristic signals of CEF at $1620 \mathrm{~cm}^{-1}$ and $1424 \mathrm{~cm}^{-1}$ correspond to the stretching and bending vibration of $\mathrm{COO}^{-}$group, respectively (Liu et al.
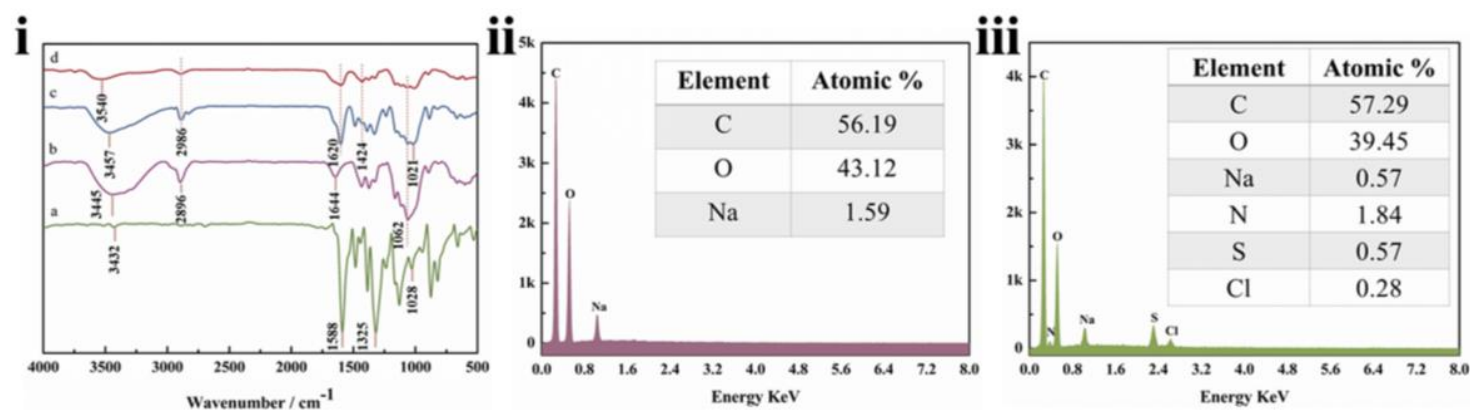

Fig. 4. (i) FTIR spectra of (a) MB; (b) cellulose fiber; (c) MB loaded CEF; (d) CEF. EDS analyses of (ii) CEF and (iii) MB loaded CEF.

\section{Effect of $p H$ value}

Generally, with varying levels of environmental $\mathrm{pH}$, adsorbents exhibit different adsorption 
221 CEF for MB mainly relies on the strong electrostatic interactions between carboxyl group and cationic

222 MB for ion exchange. The lower $\mathrm{pH}$ condition causes protonation of carboxyl group, leading to 223 electrostatic repulsion with MB. With the increasing of alkalinity, electrostatic interactions between carboxyl group and cationic MB enhances, resulting in the improvement of adsorption capacity.

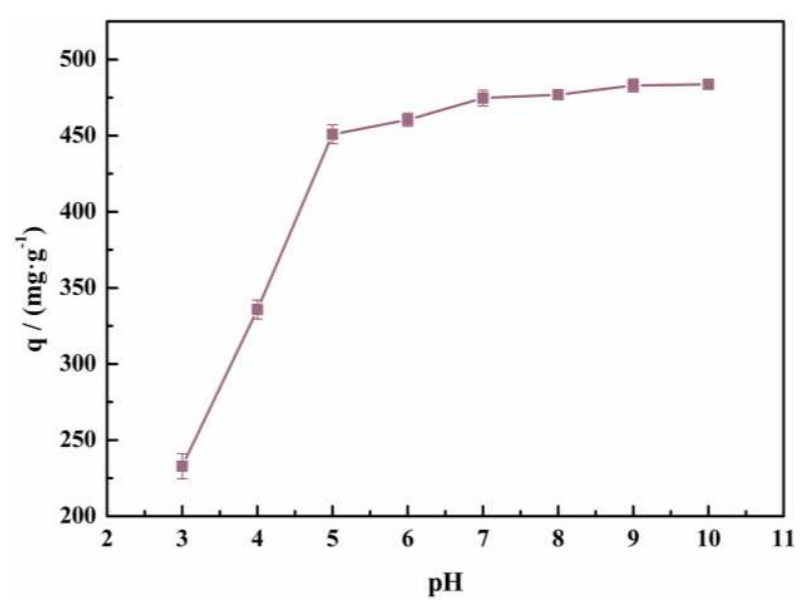

Fig. 5. The pH value effect on adsorption of CEF for MB.

Table 3 The isotherm parameters of the adsorption MB by CEF.

\begin{tabular}{ccccccc}
\multicolumn{7}{c}{ Table 3 The isotherm parameters of the adsorption MB by CEF. } \\
\hline \multirow{3}{*}{$\mathrm{T}(\mathrm{K})$} & \multicolumn{3}{c}{ Langmuir model } \\
\cline { 2 - 7 } & $\mathrm{q}\left(\mathrm{mg} \cdot \mathrm{g}^{-1}\right)$ & $\mathrm{K}_{\mathrm{L}}\left(\mathrm{L} \cdot \mathrm{mg}^{-1}\right)$ & $\mathrm{R}^{2}$ & $\mathrm{~K}_{\mathrm{F}}\left(\mathrm{L} \cdot \mathrm{mg}^{-1}\right)$ & $\mathrm{n}$ & $\mathrm{R}^{2}$ \\
\hline 298 & 409.84 & 0.2001 & 0.999 & 121.79 & 2.9830 & 0.993 \\
313 & 434.78 & 0.1944 & 0.998 & 127.46 & 2.9595 & 0.974 \\
328 & 497.51 & 0.1428 & 0.997 & 106.80 & 2.3745 & 0.968 \\
\hline
\end{tabular}

\section{Adsorption isotherms and thermodynamics}

The adsorption isotherms of CEF for MB at three different temperatures $(298,313,328 \mathrm{~K})$ were determined at $\mathrm{pH}$ 7.0, and the data were fitted by Langmuir model and Freundlich model. It obviously observed that the results are a better match with monolayer adsorption (Langmuir model) (Fig. 6a and b and Table 3). The higher the temperature, the higher the adsorption capacity. At $328 \mathrm{~K}$, the saturation capacity is $497.51 \mathrm{mg} \cdot \mathrm{g}^{-1}$. 

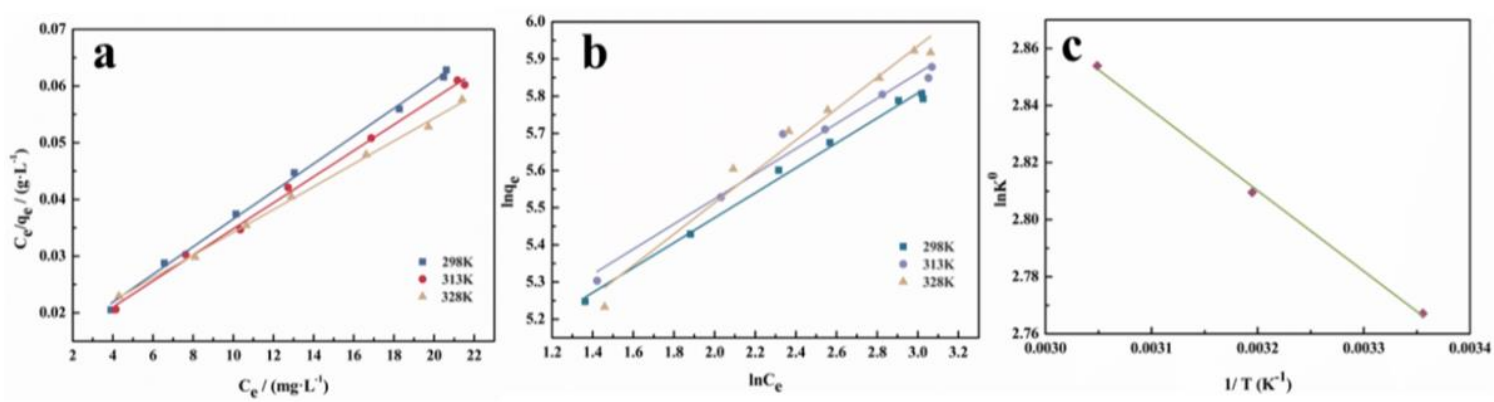

Fig. 6. (a) The Langmuir isotherm and (b) the Freundlich isotherm for the adsorption of MB. (c)The linear plots of thermodynamic for the adsorption of MB. the MB adsorption process is an endothermic and spontaneous process. This result further confirms that high temperature is beneficial to the MB adsorption onto CEF.

Table 4 Thermodynamic parameters at different temperatures.

\begin{tabular}{cccc}
\hline $\mathrm{T}(\mathrm{K})$ & $\Delta \mathrm{G}^{0}\left(\mathrm{KJ} \cdot \mathrm{mol}^{-1}\right)$ & $\Delta \mathrm{H}^{0}\left(\mathrm{KJ} \cdot \mathrm{mol}^{-1}\right)$ & $\Delta \mathrm{S}^{0}\left(\mathrm{~J} \cdot \mathrm{mol}^{-1} \cdot \mathrm{K}^{-1}\right)$ \\
\hline 298 & -6.86 & & \\
\hline 313 & -7.31 & 2.35 & \\
\hline 328 & -7.78 & & \\
\hline
\end{tabular}

The MB adsorption/removal is shown in Fig. 7a (200 ppm MB, $20 \mathrm{mg}$ CEF, pH 7.0), the dye removal reached a plateau value $\left(447.69 \mathrm{mg} \cdot \mathrm{g}^{-1}\right)$ quickly. The theoretical adsorption capacity (i.e., electrostatic adsorption capacity) calculated from the carboxyl group content in CEF (107.64 mmol/100g sample) is $344.29 \mathrm{mg} \cdot \mathrm{g}^{-1}$ (Eq. (S2)). Other factors, such as surface adsorption, van der Waals forces and/or hydrogen bonding (Liu et al. 2015), also contribute to the MB adsorption onto CEF (Fig. 7e). Notably, the adsorption capacity of CEF rapidly reached $113.13 \mathrm{mg} \cdot \mathrm{g}^{-1}(\approx 25 \%$ of its equilibrium uptake), 312.15 $\mathrm{mg} \cdot \mathrm{g}^{-1}(\approx 70 \%$ of its equilibrium uptake $)$ and $367.86 \mathrm{mg} \cdot \mathrm{g}^{-1}(\approx 82 \%$ of its equilibrium uptake $)$ in a very 

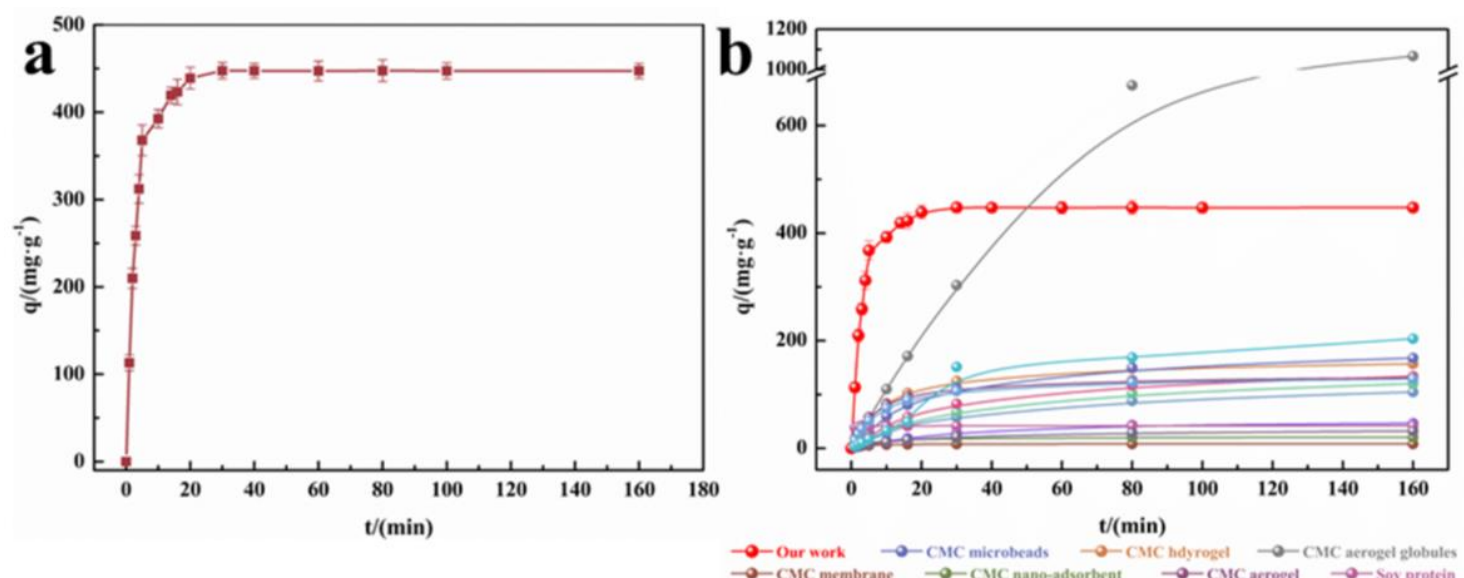
$\rightarrow$ CMC membrane $\rightarrow$ - CMC nano-adsorbent $\rightarrow$ CMC aerogel $\rightarrow-0$-Soy protein

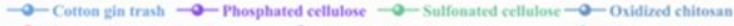
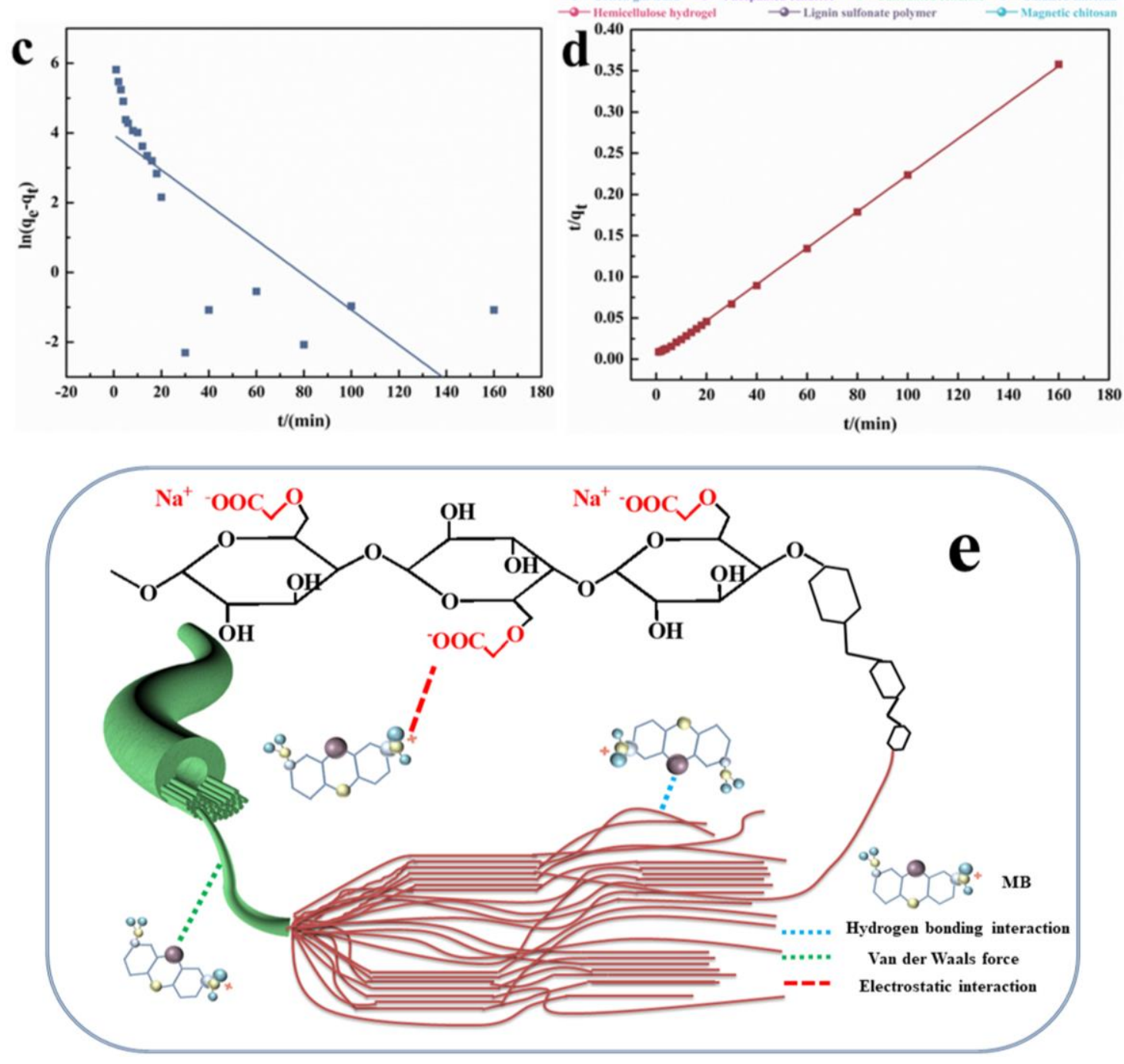

Fig. 7. (a) The adsorption capacity versus contact time for MB adsorption onto CEF. (b) Comparison of adsorption capacity versus contact time of CEF, with other cationic dye bio-adsorbents, the model dyes used are listed in Table 
S1. (c) The pseudo-first-order kinetic and (d) the pseudo-second-order kinetic plots of MB by CEF. (e) Schematic

representation of the interactions between $\mathrm{CEF}$ and $\mathrm{MB}$.

Shown in Fig. $7 \mathrm{~b}$ are the comparisons of the adsorption capacity vs time plotting of the present study and those reported in the literature for cationic dye bio-adsorbents. One striking feature is that the as-prepared CEF sample has the fastest adsorption rate among all the samples, making it an excellent adsorbent for highly efficient MB removal from wastewater.

Two kinetic models, pseudo-first order kinetics and pseudo-second order kinetics were used to analyze the MB adsorption rates of CEF. The kinetic parameters were obtained by linear regression of the plots and summarized in Table 5. The theoretical equilibrium adsorption amount from pseudo-second order kinetics (452.49 $\left.\mathrm{mg} \cdot \mathrm{g}^{-1}\right)$ is approximate the actual adsorption amount $\left(447.69 \mathrm{mg} \cdot \mathrm{g}^{-1}\right)$. Meanwhile, the value of $\mathrm{R}^{2}$ (0.9996) for pseudo-second order kinetics is much higher than that of pseudo-first order order kinetics (Fig. $7 \mathrm{c}$ and d).

Table 5 Kinetics parameters for adsorption MB of CEF.

\begin{tabular}{cccccc}
\hline \multicolumn{3}{c}{ Pseudo-first order kinetics } & \multicolumn{3}{c}{ Pseudo-second order kinetics } \\
\hline $\mathrm{K} 1\left(\mathrm{~g} \cdot \mathrm{mg}^{-1} \cdot \mathrm{min}^{-1}\right)$ & $\mathrm{qe}\left(\mathrm{mg} \cdot \mathrm{g}^{-1}\right)$ & $\mathrm{R}^{2}$ & $\mathrm{~K} 2\left(\mathrm{~g} \cdot \mathrm{mg}^{-1} \cdot \mathrm{min}^{-1}\right)$ & $\mathrm{qe}\left(\mathrm{mg} \cdot \mathrm{g}^{-1}\right)$ & $\mathrm{R}^{2}$ \\
\hline 0.05014 & 51.38 & 0.5481 & 0.00156 & 452.49 & 0.9996 \\
\hline
\end{tabular}

A device with perfect solid/liquid separation performance was designed as shown in Fig. 8a and video. Here, a non-woven porous filter material is formed by CEFs and glass fibers, and the constructed multi-channel structure similar to polymer-based ion-exchange resins prepared by porogen (Vorotyntsev et al. 2018) effectively reducing the hindrance to fluid flow and increasing the water filtration rate (Fig. 
The superior water filtration capability of adsorbent is critical, which means whether a sufficient amount of dye-containing wastewater can be treated to satisfy the practical need. In this study, water filtration capacity of CEFs filter material was evaluated at the MB concentration of $150 \mathrm{ppm}$ and volume of $50 \mathrm{~mL}$. As shown in the video and Fig. $8 \mathrm{a}$ i and ii, clean filtered water is immediately produced as the dye is poured. The absorbance of filtered water at $664 \mathrm{~nm}$, the characteristic absorption peak of MB, is 0.21 . The dye removal rate reached $99.2 \%$. More importantly, CEFs filter material basically completed the purification process within $25 \mathrm{~s}$ (Fig. 8a iii). Therefore, the filtration rate of the CEFs filter material with a thickness of $17.5 \mathrm{~mm}$ is up to $6.3 \mathrm{~m}^{3} \cdot \mathrm{m}^{-2} \cdot \mathrm{h}^{-1}$.
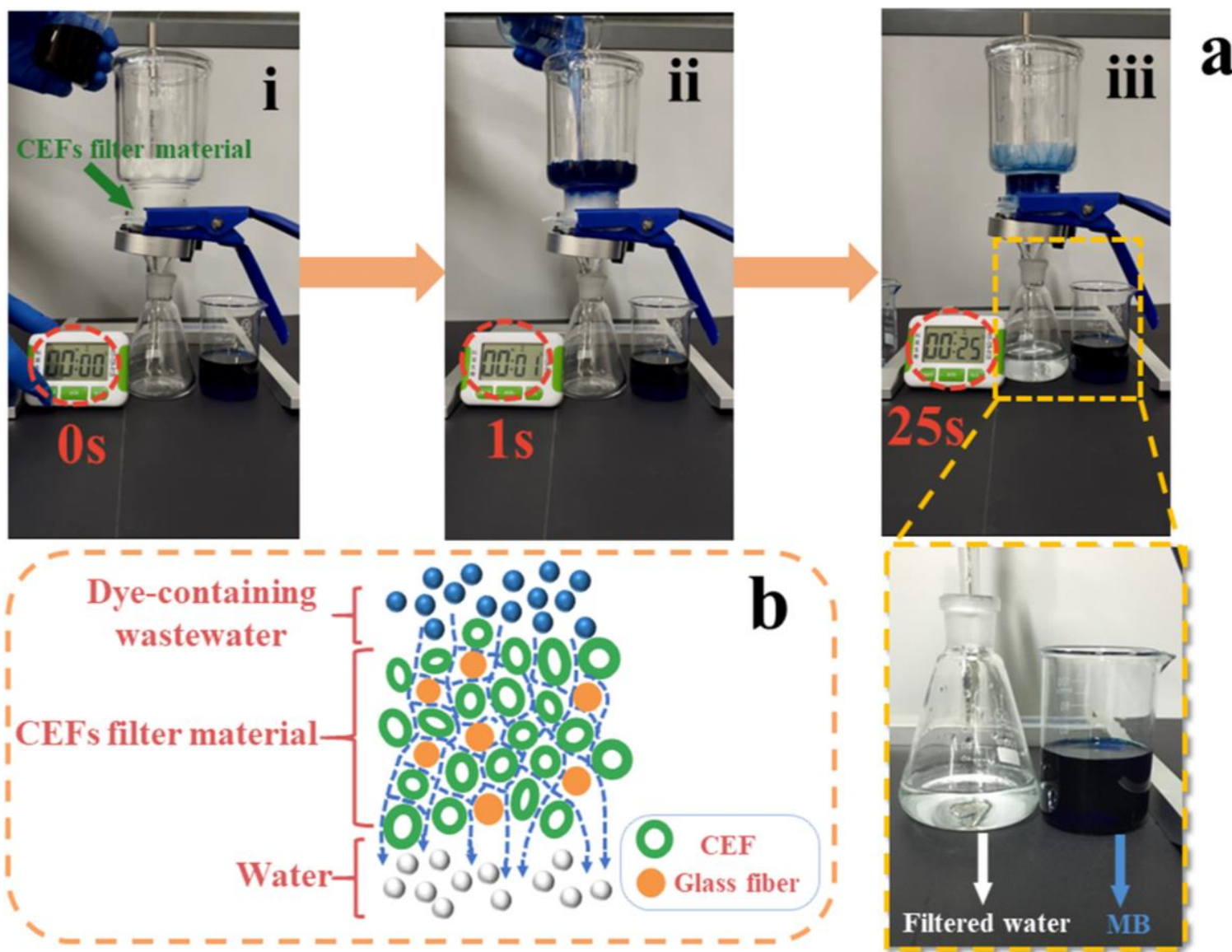

Fig. 8. (a) A rapid removal of MB from the wastewater by CEFs filter material within $25 \mathrm{~s}$. (b) Cross-sectional representation of the multi-channel CEFs non-woven materials to filter dye-containing wastewater. 
Adsorbent reuse/recycling is also of practical interest. The regeneration of dye-saturated CEFs filter practical application.

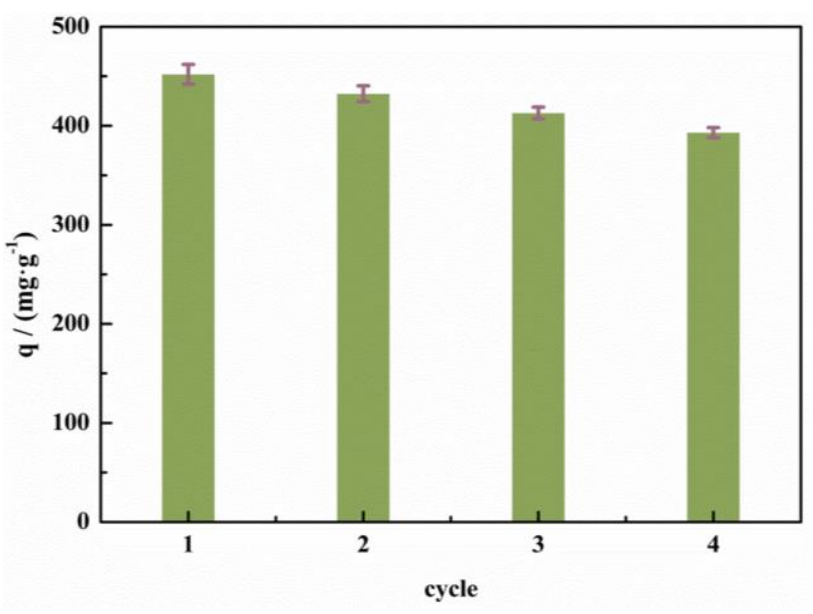

Fig. 9. Adsorption ability and reusability of CEFs filter material.

\section{Conclusion}

In summary, we synthesized a cation-exchange fibrous bio-adsorbent with desirable solid/liquid 
equilibrium uptake in just 5 min. More importantly, the CEFs filter material with perfect solid/liquid separation performance has a fast water filtration rate $\left(6.3 \mathrm{~m}^{3} \cdot \mathrm{m}^{-2} \cdot \mathrm{h}^{-1}\right)$ and is easy to regenerate. The above advantages, together with the sustainability and biodegradability demonstrate the promise of using

CEF as high-performance adsorbent for dye-containing wastewater treatment applications.

\section{Acknowledgments}

291 This work was financially supported by High-level Foreign Experts Project (GDT20186100425).

\section{Conflict of interest}

The authors declared no potential conflicts of interest with respect to the research, authorship, and/or publication of this article.

295

296

\section{References}

Abiri F, Fallah N, Bonakdarpour B (2016). Sequential anaerobic-aerobic biological treatment of colored wastewaters: Case study of a textile dyeing factory wastewater. Water Science \& Technology 75 : 1261-1269. https://doi.org/10.2166/wst.2016.531

Baeta BEL, Lima DRdS, Silva SdQ, Aquino SFd (2014). Evaluation of soluble microbial products and aromatic amines accumulation during a combined anaerobic/aerobic treatment of a model azo dye. Chem. Eng. Technol 259: 936-944. https://doi.org/10.1016/j.cej.2014.08.050

Chen LH, Zhu JY, Baez, Kitin, Elder (2016) Highly thermal-stable and functional cellulose nanocrystals and nanofibrils produced using fully recyclable organic acids. Green Chem 18: 3835-3843. https://doi.org/10.1039/C6GC00687F

Chen B, Long F, Chen S, Cao Y, Pan X (2020) Magnetic chitosan biopolymer as a versatile adsorbent for simultaneous and synergistic removal of different sorts of dyestuffs from simulated wastewater. 
Chen YS, Long YW, Li Q, Chen XH, Xu X (2018) Synthesis of high-performance sodium carboxymethyl cellulose-based adsorbent for effective removal of methylene blue and $\mathrm{Pb}$ (II). Int J Biol Macromol 126: 107-117. https://doi.org/10.1016/j.ijbiomac.2018.12.119

Dai H, Huang Y, Huang H (2017) Eco-friendly polyvinyl alcohol/carboxymethyl cellulose hydrogels reinforced with graphene oxide and bentonite for enhanced adsorption of methylene blue. Carbohydr Polym 185: 1-11. https://doi.org/10.1016/j.carbpol.2017.12.073

Haque ANMA, Remadevi R, Rojas OJ, Wang X, Naebe M (2020) Kinetics and equilibrium adsorption of methylene blue onto cotton gin trash bioadsorbents. Cellulose 27: 6485-6504. https:// doi.org/ $10.1007 / \mathrm{s} 10570-020-03238-\mathrm{y}$

Huang T, Shao YW, Zhang Q, Deng YF, Liang ZX, Guo FZ, Li PC, Wang Y (2019) Chitosan-Crosslinked Graphene Oxide/Carboxymethyl Cellulose Aerogel Globules with High Structure Stability in Aqueous and Extremely High Adsorption Ability. ACS Sustainable Chem Eng 7: 8775-8788. https:// doi.org/ 10.1021/acssuschemeng.9b00691

Jia SY, Tang DY, Peng J, Yang X, Sun ZJ (2020) Crosslinked Electrospinning Fibers with Tunable Swelling Behaviors: A Novel and Effective Adsorbent for Methylene Blue. Chem. Eng. Technol 390: 124472. https://doi.org/10.1016/j.cej.2020.124472

Kamcev J, Taylor KM, Shin DM, Jarenwattananon NN, Colwell AK (2019) Functionalized Porous Aromatic Frameworks as High-Performance Adsorbents for the Rapid Removal of Boric Acid from Water. Adv Mater 31: 1808027. https:// doi.org/ 10.1002/adma.201808027

Leon O, Alexandra MB, Soto D, Perez D, Rangel M (2018) Removal of anionic and cationic dyes with bioadsorbent oxidized chitosans. Carbohydr Polym 194: 375-383. https:// doi.org/ 10.1016/j.carbpol.2018.04.072 
Li Y, Xiao HN, Pan YF, Wang LD (2018) Novel Composite Adsorbent Consisting of Dissolved Cellulose Fiber/Microfibrillated Cellulose for Dye Removal from Aqueous Solution. ACS Sustainable Chem Eng 6: 6994-7002. https:// doi.org/ 10.1021/acssuschemeng.8b00829

Li Z, Potter N, Rasmussen J, Weng J, Lv G (2018) Removal of rhodamine 6G with different types of clay minerals. Chemosphere 202(JUL.): 127-135. https:// doi.org/ 10.1016/j.chemosphere.2018.03.071

Liu F, Zou H, Hu J, Liu H, Huo Y (2016a) Fast removal of methylene blue from aqueous solution using porous soy protein isolate based composite beads. Chem Eng Technol 287: 410-418. https:// doi.org/ 10.1016/j.cej.2015.11.041

Liu J, Chu H, Wei H, Zhu H, Wang G, Zhu J, He J (2016b) Facile fabrication of carboxymethyl cellulose sodium/graphene oxide hydrogel microparticles for water purification. Rsc Adv 6: 50061-50069. https://doi.org/10.1039/C6RA06438H

Liu L, Gao ZY, Su XP, Chen X, Jiang L, Yao JM (2015). Adsorption Removal of Dyes from Single and Binary Solutions Using a Cellulose-based Bioadsorbent. ACS Sustainable Chem Eng 3: 432-442. https:// doi.org/ 10.1021/sc500848m

Neethu N, Choudhury T (2018)Treatment of Methylene Blue and Methyl Orange Dyes in Wastewater by Grafted Titania Pillared Clay Membranes. Recent. Pat. Nanotech 12: 200-207. https:// doi.org/ $10.2174 / 1872210512666181029155352$

Nguyen CH, Juang RS (2019) Efficient removal of methylene blue dye by a hybrid adsorption-photocatalysis process using reduced graphene oxide/titanate nanotube composites for water reuse. J. Ind. Eng 76: 296-309. Chem. https:// doi.org/ 10.1016/j.jiec.2019.03.054

Oveisi M, Asli MA, Mahmoodi NM (2017) MIL-Ti metal-organic frameworks (MOFs) nanomaterials as superior adsorbents: Synthesis and ultrasound-aided dye adsorption from multicomponent 
wastewater systems. J. Hazard. Mater 347: 123-140. https:// doi.org/ 10.1016/j.jhazmat.2017.12.057

Peláez-Cid A-A, Herrera-González A-M, Salazar-Villanueva M, Bautista-Hernández A (2016) Elimination of textile dyes using activated carbons prepared from vegetable residues and their characterization. J. Environ. Manage 181: 269-278. https:// doi.org/10.1016/j.jenvman.2016.06.026

Prabakaran E, Pillay K (2019) Synthesis of N-doped ZnO nanoparticles with cabbage morphology as a catalyst for the efficient photocatalytic degradation of methylene blue under UV and visible light. RSC Adv 9(13): 7509-7535. https:// doi.org/10.1039/C8RA09962F

Qi H, Wei T, Zhao W, Zhu B, Zhu J (2019) An Interfacial Solar-Driven Atmospheric Water Generator Based on a Liquid Sorbent with Simultaneous Adsorption-Desorption. Adv Mater 31: 1903378. https:// doi.org/ 10.1002/adma.201903378

Rethinasabapathy M, Kang SM, Lee I, Lee GW, Hwang SK, Roh C, Huh YS (2018) Layer-Structured POSS-Modified Fe-Aminoclay/Carboxymethyl Cellulose Composite as a Superior Adsorbent for the Removal of Radioactive Cesium and Cationic Dyes. Ind Eng Chem Res 57: 13731. https:// doi.org/ 10.1021/acs.iecr.8b02764

Sabarish R, Unnikrishnan G (2018). Polyvinyl alcohol/carboxymethyl cellulose/ZSM-5 zeolite biocomposite membranes for dye adsorption applications. Carbohydr. Polym 199: 129-140. https://doi.org/10.1016/j.carbpol.2018.06.123.

Segal L, Creely J, Martin Jr A, Conrad C (1959). An empirical method for estimating the degree of crystallinity of native cellulose using the X-ray diffractometer. Text Res J 29: 786-794.

Shen GQ, Pan L, Zhang RR, Sun SC, Hou F, Zhang XW, Zou JJ( 2020). Low-Spin-State Hematite with Superior Adsorption of Anionic Contaminations for Water Purification. Adv. Mater 32: 1905988. https:// doi.org/ 10.1002/adma.201905988

Shi H, Li J, Shi D, Shi H, Feng B, Li W, Bai Y, Zhao J, He A (2015) Combined Reduction/Precipitation, 
Chemical Oxidation, and Biological Aerated Filter Processes for Treatment of Electroplating Wastewater. Separationence

$\&$ Technology 50(15): 2303-2310. https://doi.org/10.1080/01496395.2015.1049365

Silva MS, Silva LS, Ferreira FJL, Bezerra RDS, Marques TMF, Meneguin AB, Barud HS, Osajima JA, Silva Filho EC (2020) Study of interactions between organic contaminants and a new phosphated biopolymer derived from cellulose. Int $\mathrm{J}$ Biol Macromol 146: 668-677. https://doi.org/10.1016/j.ijbiomac.2019.12.121.

Sun X, Gan Z, Jing Z, Wang H, Jin Y (2015) Adsorption of methylene blue on hemicellulose - based stimuli - responsive porous hydrogel. J Appl Polym Sci 132: 41606. https:// doi.org/ 10.1002/app.41606

Tang Y, Hu T, Zeng Y, Zhou Q, Peng Y (2014) Effective adsorption of cationic dyes by lignin sulfonate polymer based on simple emulsion polymerization: isotherm and kinetic studies. Rsc Adv 5: 3757-3766. https:// doi.org/ 10.1039/C4RA12229A

Vorotyntsev AV, Petukhov AN, Makarov DA, Razov EN, Vorotyntseva IV, Nyuchev AV, Kirillova NI, Vorotyntsev VM (2018) Synthesis, properties and mechanism of the ion exchange resins based on 2-methyl-5-vinylpyridine and divinylbenzene in the catalytic disproportionation of trichlorosilane. Appl Catal B: Environ 224: 621-633. https://doi.org/10.1016/j.apcatb.2017.10.062

Xiang C, Wang C, Guo RH, Lan JW, Lin SJ, Jiang SX, Lai XX, Zhang Y, Xiao HY (2018) Synthesis of carboxymethyl cellulose-reduced graphene oxide aerogel for efficient removal of organic liquids and dyes. J. Mater. Sci. 54: 1872-1883.https://doi.org/10.1007/s10853-018-2900-5.

Xu YJ, Sun QH, Jin QC, Li Q (2015) Adsorptive removal of anionic dyes from aqueous solutions using microgel based on nanocellulose and polyvinylamine. Bioresource Technol 197: 348-355. 
Zhou Y, Zhang M, Wang X, Huang Q, Min Y, Ma T, Niu J (2014) Removal of Crystal Violet by a Novel 
Figures
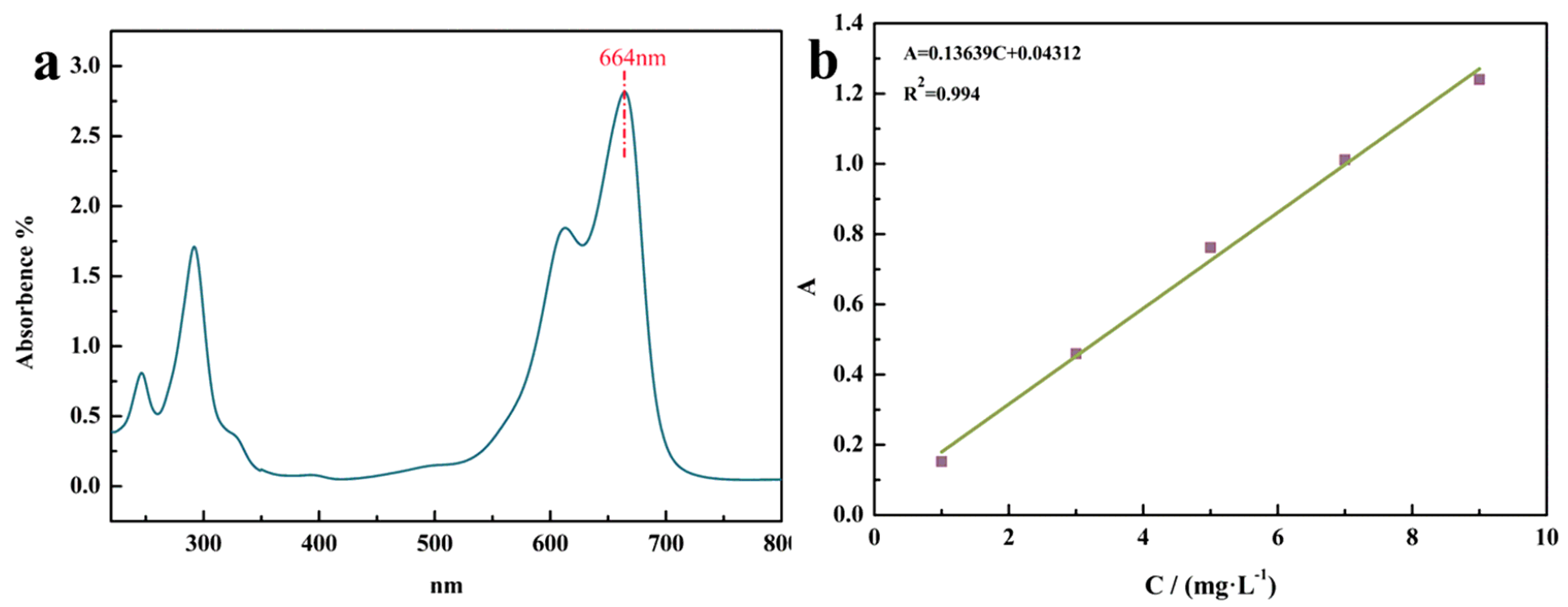

Figure 1

(a) UV-Vis spectra of MB; (b) A-C curves of MB.
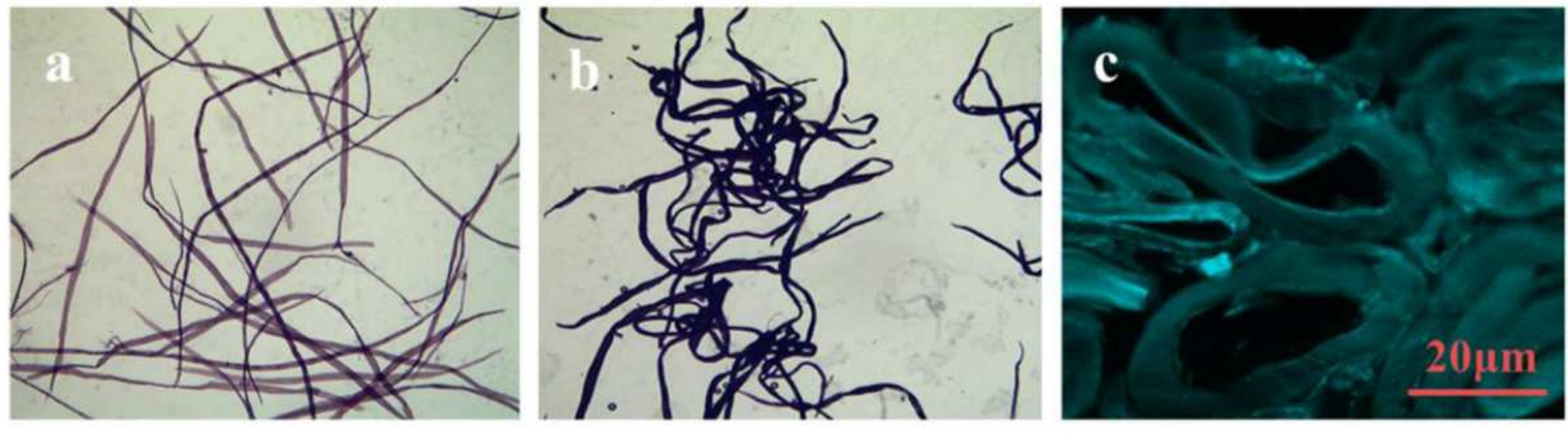

Figure 2

The optical micrographs of (a) cellulose fibers $(\times 40)$ and (b) CEFs $(\times 40)$. (c) The cross-sectional of CEFs (with fluorescent active labelling). 


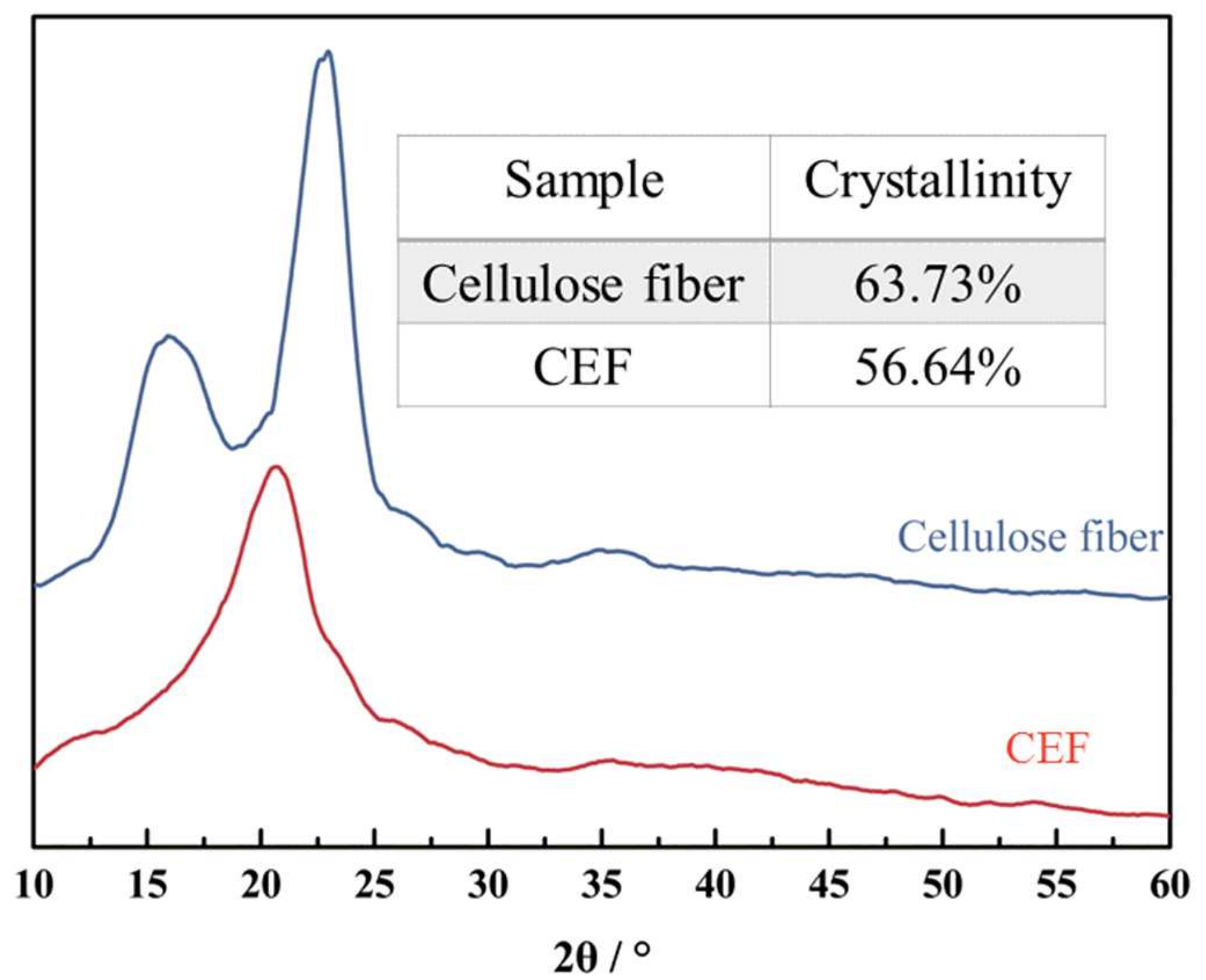

Figure 3

XRD spectra of cellulose fiber and CEF.
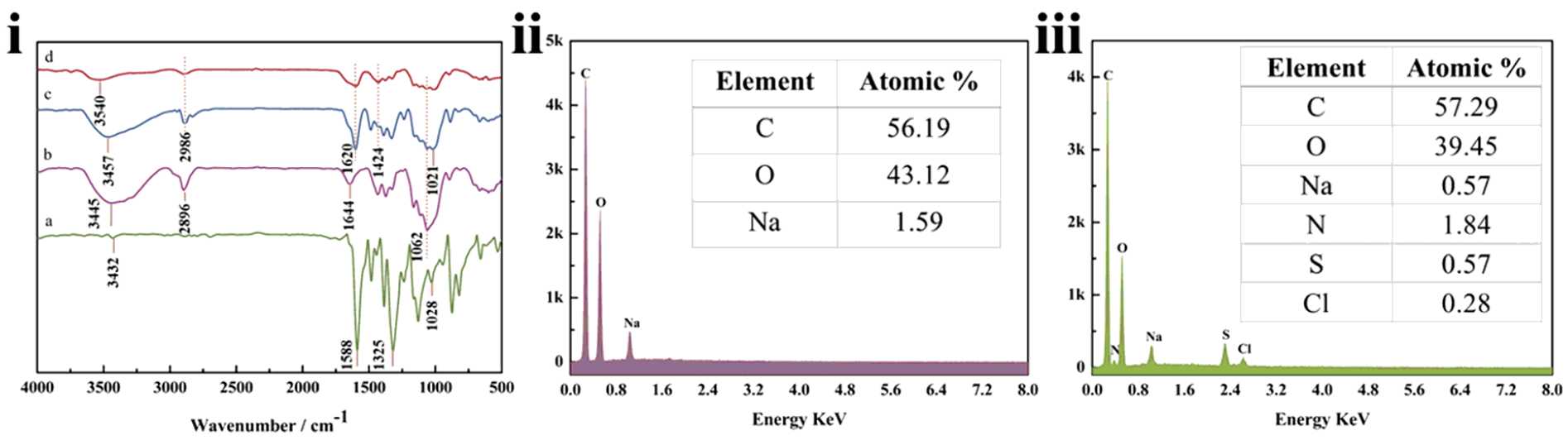
Figure 4

(i) FTIR spectra of (a) MB; (b) cellulose fiber; (c) MB loaded CEF; (d) CEF. EDS analyses of (ii) CEF and (iii) MB loaded CEF.

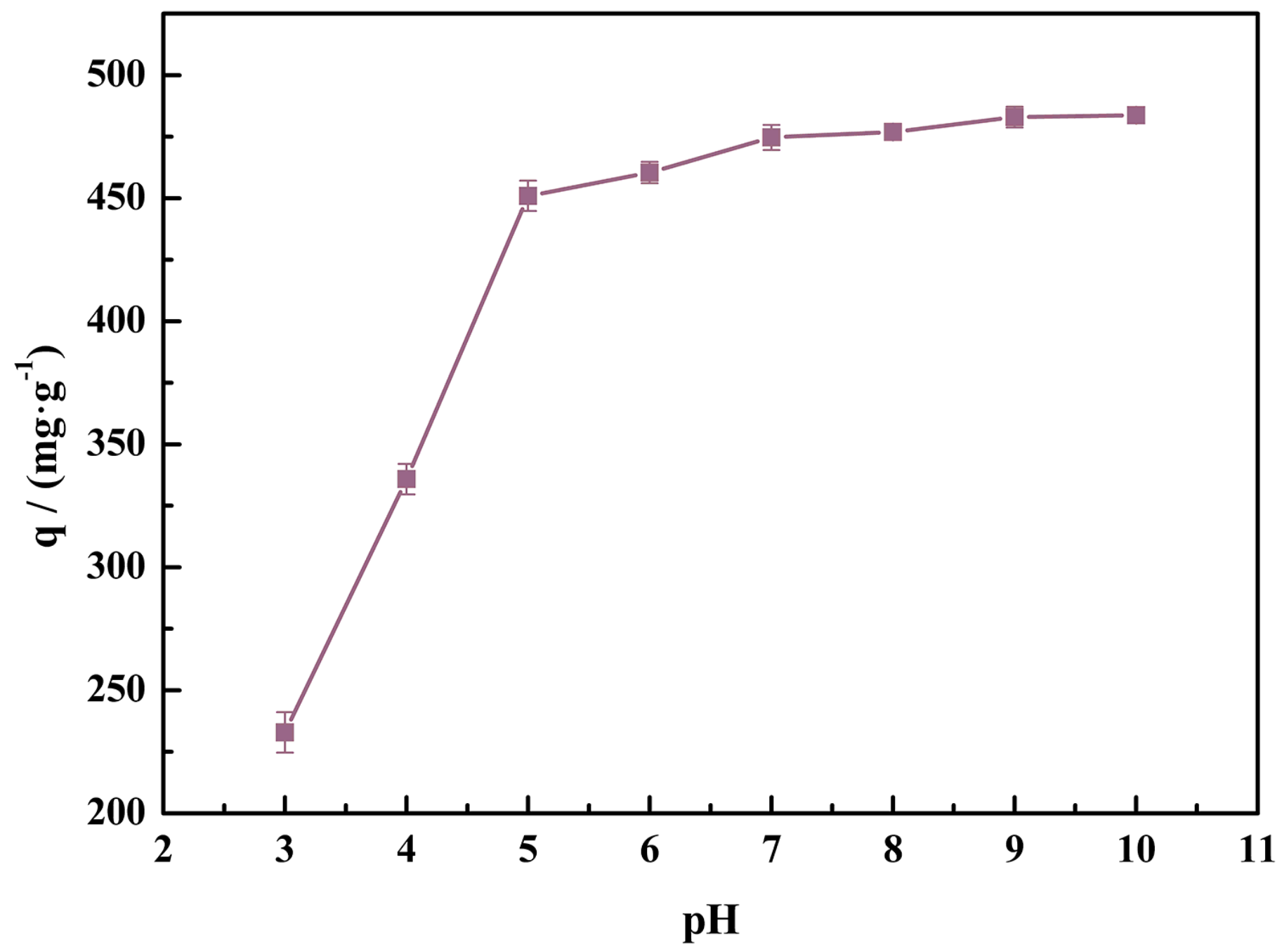

Figure 5

The $\mathrm{pH}$ value effect on adsorption of CEF for MB. 

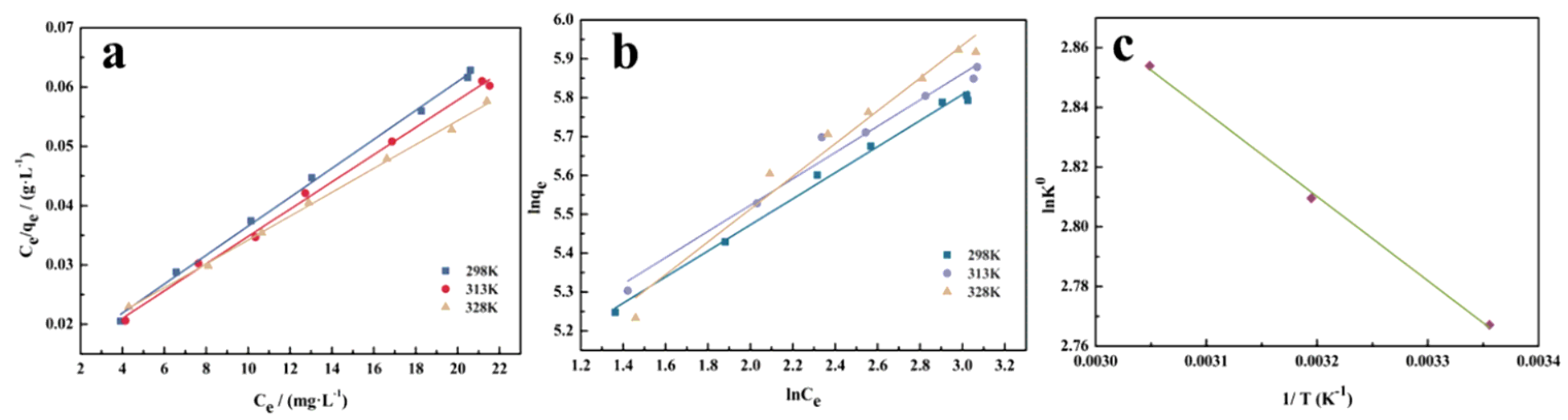

Figure 6

(a) The Langmuir isotherm and (b) the Freundlich isotherm for the adsorption of MB. (c)The linear plots of thermodynamic for the adsorption of MB. 

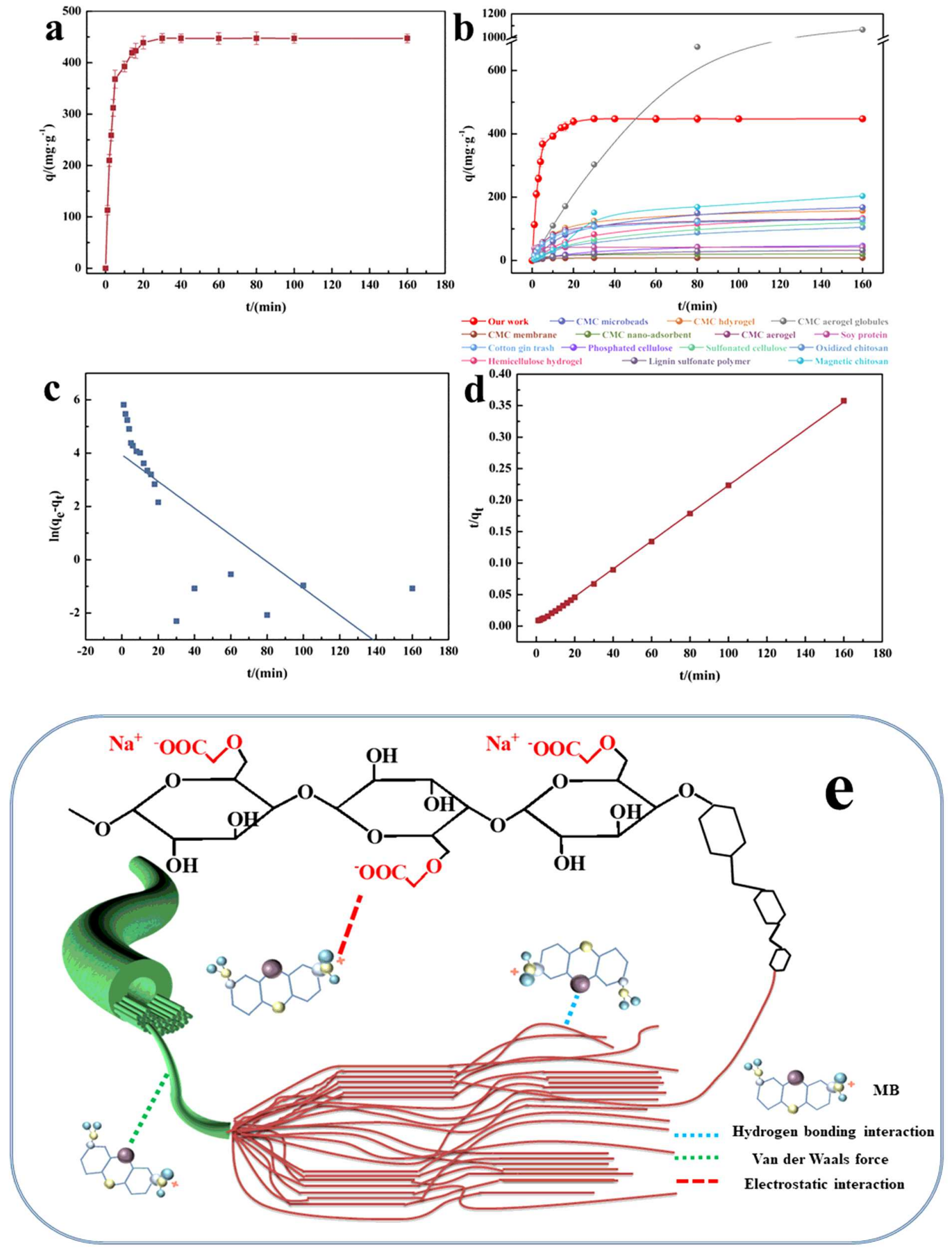

Figure 7

(a) The adsorption capacity versus contact time for MB adsorption onto CEF. (b) Comparison of adsorption capacity versus contact time of $\mathrm{CEF}$, with other cationic dye bio-adsorbents, the model dyes used are listed in Table S1. (c) The pseudo-first-order kinetic and (d) the pseudo-second-order kinetic plots of MB by CEF. (e) Schematic representation of the interactions between CEF and MB. 

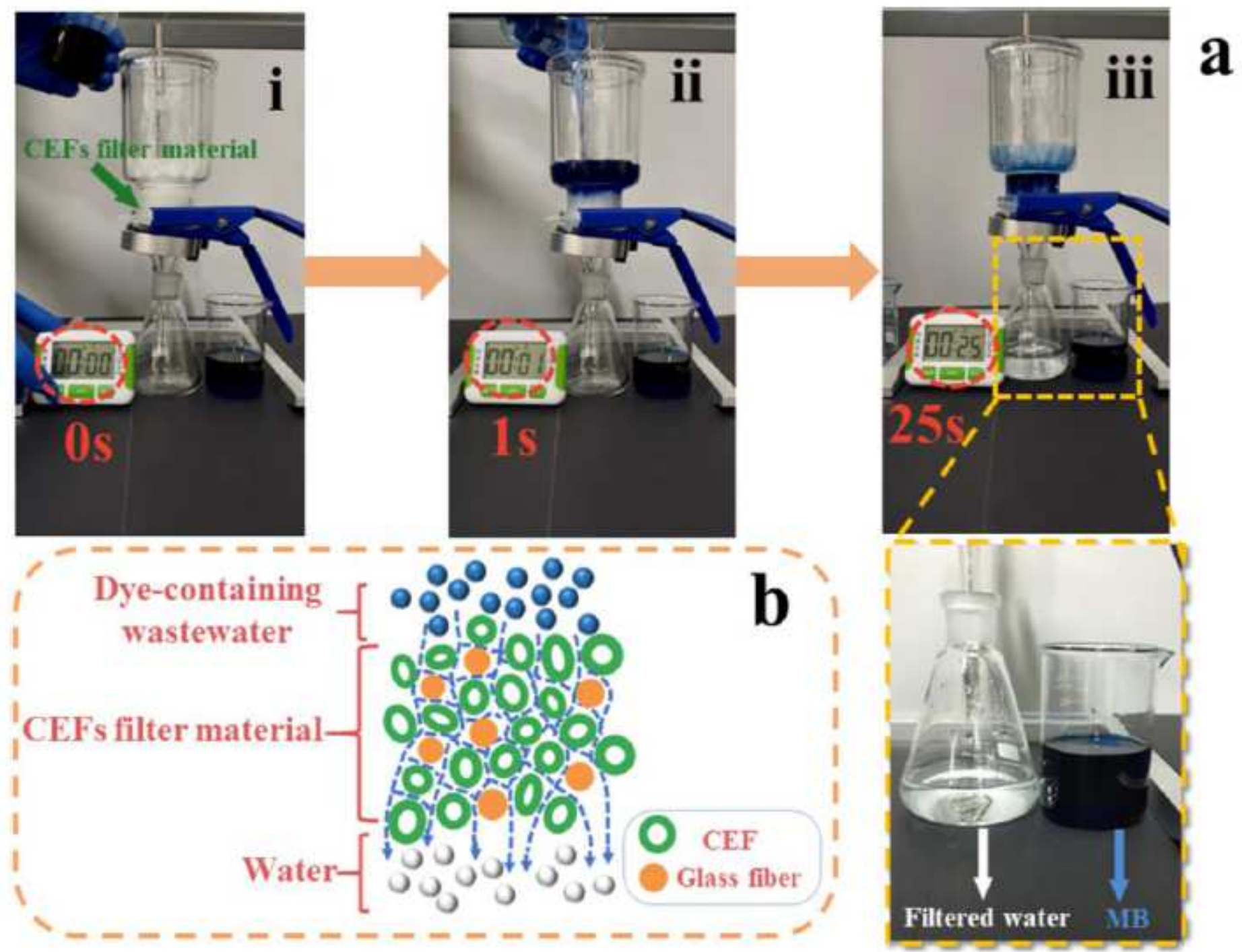

Figure 8

(a) A rapid removal of MB from the wastewater by CEFs filter material within $25 \mathrm{~s}$. (b) Cross-sectional representation of the multi-channel CEFs non-woven materials to filter dye-containing wastewater. 


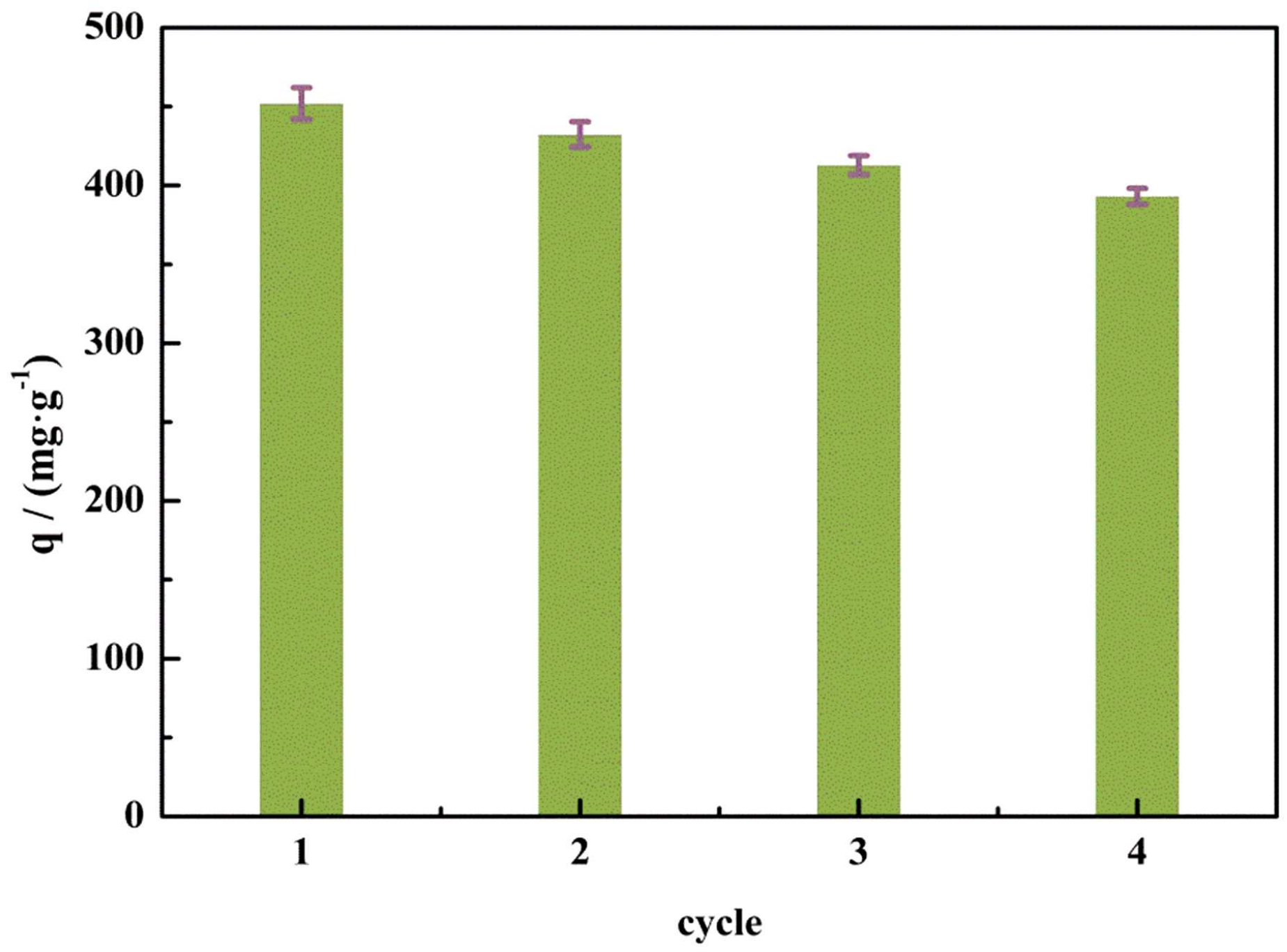

Figure 9

Adsorption ability and reusability of CEFs filter material.

\section{Supplementary Files}

This is a list of supplementary files associated with this preprint. Click to download.

- Graphicalabstract.png

- SupplementaryMaterial.docx

- vedio.mp4 